\title{
Congresos virtuales: una prueba de madurez de las Sociedades Científicas
}

\author{
Lola Andreu-Periz \\ Profesora Honorifica de la Universitat de Barcelona (UB). España
}

Como citar este artículo:

Andreu-Periz L. Congresos virtuales: una prueba de madurez de las Sociedades Científicas.

Enferm Nefrol. 2021 Jul-Sep;24(3):217-8

Se acerca el mayor acontecimiento sobre el que pivota gran parte de la actividad de nuestra Sociedad, el Congreso Anual ${ }^{1}$, que por imperativo sanitario ha de volver a hacerse de forma virtual. Sabemos que este evento es un elemento clave para la difusión de nuestro conocimiento, y resulta fundamental para debatir asuntos de interés, o poner en común diferentes puntos de vista por parte de los asistentes.

La COVID-19 ha trastocado los planes de millones de personas en todo el mundo, más allá de las cifras de infectados y fallecidos, el impacto del virus en la vida cotidiana y en la economía está siendo incalculable. Las medidas impuestas por los gobiernos para contener la propagación de la enfermedad motivaron en un primer momento cancelaciones o aplazamientos de eventos por todo el mundo. Pronto se hizo patente que la situación se alargaría y se pusieron en marcha soluciones que minimizaran su impacto.

La Junta Permanente de SEDEN reaccionó con rapidez y puso su infraestructura y organización al servicio de un proyecto que permitió en un tiempo récord organizar un congreso virtual que obtuvo unos excelentes resultados. Se palió el desencanto inicial de no poder reunir a los asociados con la esperanza de que al año siguiente se volvería a la normalidad y mantuvo la cita de Granada para este año.

Pero esta, como otras previsiones más optimistas, se ha visto desbordada por los acontecimientos y desafortunadamente, la persistencia de la epidemia aconseja que los encuentros científicos sean virtuales.
No nos encontramos ante un fenómeno nuevo y aunque la pandemia ha acelerado su difusión en los últimos años los congresos, seminarios, jornadas y otros formatos de eventos, ya no son solo presenciales. Una reunión virtual es una alternativa a los congresos tradicionales que tiene, entre otras ventajas, incrementar su difusión, el acceso a un número más amplio de usuarios y abarata los costes. En nuestro medio es importante resaltar que facilita la presencia de ponentes internacionales y permite la presentación de tecnologías difíciles de transportar. Por otra parte, para los asistentes, la posibilidad de grabar y conservar el contenido de las sesiones permite escuchar las distintas ponencias, a su ritmo, en un espacio tranquilo, y la conexión a través de Internet le permite hacer preguntas o participar en las diversas actividades que se ofrezcan durante el evento.

Esto no quiere decir que el Congreso presencial vaya a caer en desuso, sin duda, la mejor manera de encontrarnos e interaccionar es el contacto directo y presencial, entre los asistentes. Estrechar una mano, la emoción de encontrarse con un amigo, abrazarlo o simplemente hacerse un selfie ante un monumento de la ciudad anfitriona son irremplazables.

Además hay otros aspectos a considerar, la creatividad del grupo se resiente con la virtualidad, y la implicación en la organización de un congreso presencial del servicio de nefrología anfitrión enriquece a la Sociedad puesto que aporta su dinámica y suponen un aliciente para sus miembros. Para la ciudad que acoge el evento hay muchos beneficios y los asistentes pueden disfrutar a la vez de ciencia, cultura y porque no, de un esparci- 
miento bien ganado tras largas y muchas veces duras jornadas de trabajo.

Hacer pronósticos siempre es arriesgado y más en estos tiempos inciertos, pero en un futuro en el que deseamos que la presencialidad impere, la tecnología de la información se presenta como un aliado fundamental al que no olvidar y formatos mixtos pueden ayudar a compaginar necesidades y prudencia.

Nos vemos pronto en la pantalla de nuestro dispositivo con la fundamentada esperanza de vernos "de verdad" el próximo año.

\section{Bibliografía}

1. Sociedad Española de Enfermería Nefrológica. Madrid [consultado 10 Ago 2021]. Disponible en https:// www.congresoseden.es.

Este artículo se distribuye bajo una Licencia Creative Commons Atribución-NoComercial 4.0 Internacional. https://creativecommons.org/licenses/by-nc/4.0/

Open Access (C) (7) 